\title{
8 Lessons of Massachusetts for EMU
}

\author{
PAUL KRUGMAN
}

\author{
in Torres F., Giavazzi F. (eds.) \\ Adjustment and growth in the European Monetary Union \\ Cambridge University Press, 1993
}

\section{Introduction}

Over the past decade the European Community has made great strides towards becoming a fully unified economic entity. Border obstacles and regulatory barriers to an integrated market for goods and services have been removed in the drive towards 1992; now, as the economic and monetary union (EMU) moves forward, an integrated capital market and eventually a common currency seem all but assured. By the end of the twentieth century Europe should, in many respects, constitute as unified and integrated an economy as the United States of America.

Most economists (myself included) view this as a generally good thing. Yet at any given time not everyone in the USA is entirely happy to be part of such a unified, integrated economy. In particular, over the past decade several regional economies within the United States have been subject to large adverse shocks - shocks which have arguably been so large precisely because the US economy is so integrated - for which they have had essentially no policy recourse simply because the US already has the common currency that EMU is supposed to produce for Europe.

The most intellectually influential of the regional crises in the US has been the recent slump in New England - the events are dramatic enough to be worth noting in any case, but proximity to certain univerisities has not hurt their academic visibility! The New England story is by now familiar in the US, but may be worth reviewing for Europeans.

New England is a region of about 10 million people. Like other regions in the US, it is highly specialized. Its 'export' base - those industries that sell primarily to customers outside the region - is concentrated in several narrow high technology sectors: mini-computers, advanced medicine, precision military hardware. During most of the 1980s, these sectors thrived. As computing power grew, many businesses shifted from the large mainframe computers made by IBM to the mini-computers manu- 
factured by Massachusetts firms such as Digital Equipment; the large Reagan-era defence budgets concentrated on high-technology hardware, for example, the Patriot missile manufactured by Massachusetts-based Raytheon, and so on. This export boom had both a multiplier and an accelerator effect on the local economy: employment grew in non-traded sectors such as retailing, and a commercial real estate boom led to a surge in construction employment. In late 1987 Massachusetts had an unemployment rate of only $2.5 \%$, less than half the national average.

But then the bottom fell out. Demand shifted away from New England products: personal micro-computers began to displace office minicomputers, defence spending fell. The building boom collapsed as an excess supply of new construction in the region became apparent. Within the space of three years the unemployment rate nearly quadrupled.

If New England had been a sovereign country, it might have devalued its currency and/or pursued an expansionary monetary policy. In fact, not only were these options not available, but a budget crisis forced fiscal policy to move in a pro-cyclical direction, exacerbating the slump.

When will the New England economy turn around? Based on previous regional experience in the US (which will be discussed later), the maximum likelihood answer is never. To be more specific: there is no reason to expect the New England region ever to regain its pre-slump share of US employment. The unemployment rate should gradually decline, and move towards the national average, but this will happen primarily through emigration of labour rather than through a return of jobs.

The argument of this chapter is that the New England experience is a particularly grim illustration of some of the difficulties that EMU will face at a regional level. The combined effects of 1992 and EMU will reinforce many of the conditions that allow a regional crisis of this kind. These include:

Regional specialization: US regions are much more specialized than areas of corresponding size in Europe. This greater degree of specialization has been fostered by the greater integration of the US market, an integration that Europe now seeks to emulate. Increased specialization in turn leads to:

Instability of regional exports: Because US regions are highly specialized, shifts in tastes and especially in technology lead to large and erratic shifts in exports. European regions can look forward to similar shocks, ${ }^{1}$ with the effect of these export shifts assigned by:

Pro-cyclical capital movements: Regional export booms are reinforced by investment booms. Although balance of payments 
data are not available, there is little question that New England experienced capital inflows during its boom years, magnifying the boom, and that these changed to capital outflows during the slump, helping to deepen that slump. Economic and monetary union will, of course, help to make capital more mobile within Europe, actually reinforcing instability at this level, while also contributing to:

Divergent long-run growth: US regions show marked differences in growth rates, with no tendency to return toward historical levels of relative output or employment (indeed, there is high serial correlation of growth). This divergence has a great deal to do with high factor mobility, which will of course be reinforced in Europe both by 1992 and by EMU. When the export basket of a US region falls on hard times, that region normally simply sheds capital and labour rather than experiencing a real depreciation sufficient to acquire new export sectors.

The argument of this chapter, then, is that 1992/EMU will combine to make American-style regional crises more common and more severe within the European Community. And it is immediately apparent that Europe will have a problem if it starts to experience American-style regional slumps without American-style fiscal federalism. The argument suggests, in other words, that some kind of policy reform will be necessary if the increasingly unified European economy is not to pay an even higher price for that unification than the US does.

The rest of the chapter is in four parts. Section 2 offers some theoretical analysis of the reasons why 1992/EMU will lead to greater regional instability and greater divergence in regional growth rates. Section 3 offers a rough survey of empirical evidence bearing on this analysis. In Section 4 the implications for stabilization policy are analysed. Finally, Section 5 offers a speculative look at the longer-term issues of regional growth policy.

\section{Integration, regional specialization and regional stability}

Most economists believe that international trade and factor mobility promote equalization of factor prices; this is probably correct although $\mathbf{I}$ will put forward a few doubts in Section 5. It might be imagined, on first thoughts, that eliminating explicit obstacles to trade, harmonizing regulations that would otherwise segment markets, and increasing the mobility of labour and capital, would lead not only to convergence in factor prices but to convergence in economic structure and in growth rates. In fact, however, both theory and evidence suggest that the contrary is the case: a 
more integrated market leads to divergence in both the economic structure and the growth rates of regions.

We may consider each of these issues in turn.

\subsection{Integration and specialization}

It is, of course, the essential point of most trade theory that economic integration allows regions to specialize. At one time, most agricultural land was devoted to producing foodstuffs for local consumption; today, most agricultural regions in the US are highly specialized, devoted to producing a few crops for which the soil and climate are highly suited, but correspondingly vulnerable to market fluctuations in those crops.

For regional issues both in the US and in the EC, however, the key aspect of regional specialization is the dependence of regional economies on export clusters held together by Marshallian external economies. Thus the New England boom and slump were tied to the fortunes of Route 128; the fortunes of northern California to those of Silicon Valley; and so on. Are such regional clusters more likely to form in a more integrated economy?

The answer is definitely yes. A reduction in the transactions costs between two regions, whether these costs take the form of transportation expenses, tariffs, or disparities in regulation, will make it more likely that any given degree of external economies will be sufficient to lead to geographical concentration of an industry.

This point can be made crudely in a diagram such as Figure 8.1. In the diagram we imagine an industry which can operate in either of two locations, each of which also has a local demand for the industry's products. We also assume that demand is completely price-inelastic, so that we may take the total industry output $O O$ as fixed, with sales of $O Q$ in one region, $Q O^{*}$ in the other. The industry is assumed to be perfectly competitive but subject to location-specific external economies; thus the downward-sloping schedule $C C$ (measured from the left) represents the supply curve in the first region, the schedule $C^{*} C^{*}$ (measured from the right) the supply curve in the second.

Now we ask: is it possible for both regions to produce in this industry, or will external economies lead the industry to concentrate in one location? Consider a situation in which each region is self-sufficient, with $O Q$ produced in the first region, $Q O^{*}$ in the second. As drawn here, this would give the first region a cost $c$ that is lower than the other region's cost $c^{*}-$ a cost advantage that may be the result either of a larger local market, or because of some factor cost advantage. But this will not necessarily lead to concentration of the industry. If the transaction cost 


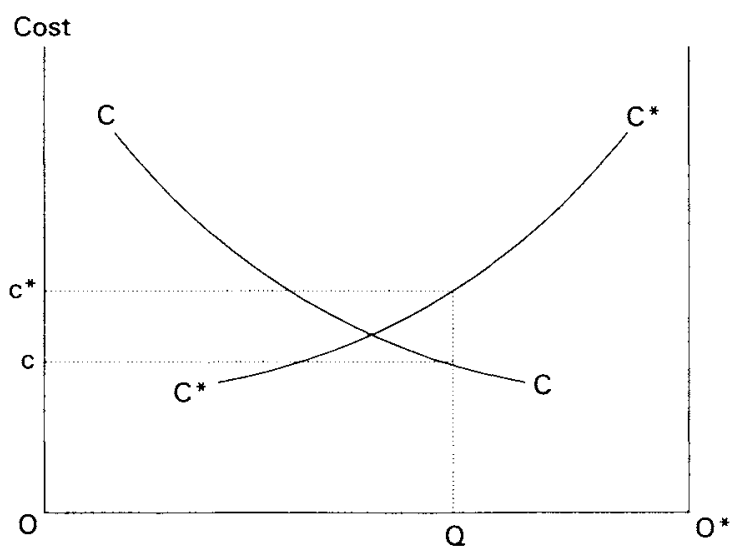

Figure 8.1 Geographical concentration

between the regions exceeds $c^{*}-c$, a geographically dispersed industry is a stable equilibrium. If the transaction cost should then be reduced, however, say by harmonization of regulations and elimination of border posts, the result would be a snowballing of advantage: the cost advantage in Region 1 would lead to an expansion of its industry and a contraction of the industry in Region 2; this would reinforce the cost disparity, and so on until the process produced a geographically concentrated industry. Other industries might, of course, end up concentrated in Region 2 in the same way. So a reduction of transaction cost would ordinarily lead to a divergence between regions in terms of their industrial structure, and increased specialization of any particular region.

It might be objected, with considerable justification, that this is too 'black-boxy' an approach. In particular, what we call external economies are often market-size effects; will not greater integration of markets make it less necessary to be in the same country as other firms in order to have access to the forward and backward linkages they generate? (For example, will we need a Silicon Valley when hackers can do everything they want from cabins in the woods?)

The answer is yes - but the presumption is still that increased integration will lead to greater geographical concentration of industries. A highly stylized example (suggested in Krugman (1991) but sketched out at slightly greater length here) may make the point. Imagine an industry consisting of a number of symmetric firms, all of whom in addition to selling to a market of final consumers find their output used as intermediate inputs by each other. We suppose that each firm sells a total of $x$ units, with a fraction $\mu$ sold as intermediate goods within the industry and the 
rest to consumers outside the industry. Consumers are in two locations, 1 and 2 , with equal final demand.

Some special cost and pricing assumptions will make this a tractable model. First, assume that firms charge customers a price $p$ that is independent of the actual cost of delivering the product. ${ }^{2}$ This implies that they must absorb any transportation costs. Second, assume that production costs take the form $F+c x$, where $F$ is a fixed cost that must be incurred for every production facility. Third, assume that there is a transportation cost $t$ for every unit shipped between locations. We may now ask the following: when is a concentration of the industry in only one region an equilibrium?

Suppose that all production were concentrated in one location. Then each firm would sell $(1-\mu) x / 2$ units to final consumers in each location, plus an additional $\mu x$ units to other firms in the cluster. Clearly, if a firm were to choose to produce in only one place it would choose the location of the existing cluster, in order to minimize transportation costs. (Note that this is a kind of external economy which holds the cluster together, but it is an external economy which is derived from market size - in Hirschmann's terminology, it is a backward linkage effect). But the firm might choose to open another plant. This would mean incurring an extra fixed cost $F$, but would save transport costs $t(1-\mu) x / 2$. Thus geographic concentration of the industry will be an equilibrium only if $F>t(1-\mu) x / 2$.

This criterion is more likely to be satisfied the higher is $F$ (loosely, the more important are economies of scale; the higher is $\mu$ ); in other words, the stronger are intra-industry linkages and, crucially for the argument in this chapter, the lower are transportation/transaction costs $t$. This may at first seem surprising. The lower are transportation costs, the less necessary is it to be close to an industry cluster in order to benefit from its linkages, and thus we might expect to find that the incentive to concentrate would be less. In this example, however, lower transport costs make geographical concentration more attractive for each individual firm, and as long as this concentration occurs, it will take place at the cluster.

The important point is that even when we attempt to formalize the emergence of external economies in a way that does not simply assume that they are localized, the idea that lower transport costs fosters geographical concentration still seems to hold.

Now imagine two continents. On one continent national governments have traditionally thrown up barriers to trade that have limited the formation of geographically concentrated industries. The other has long been run by a single government the constitution of which prohibits obstacles to inter-regional trade. We would then expect to find that 
regional economies on the first continent would be more diversified and hence more similar in structure than those on the second.

As we will see in the next section, a comparison between Europe and the United States does in general fit this description.

Presumably the United States gains from the efficiencies of specialization, from the greater ability to exploit external economies and linkages that concentration of industries provides. The penalty is that regional economies, being less diversified, are more subject to technology and demand shocks. This leads to a greater risk of severe region-specific recessions. It also leads, in the presence of high factor mobility, to large divergences in long-term growth rates.

\subsection{Factor mobility and long-run growth}

It is possible to imagine an economy in which free movement of goods and services allows extensive regional specialization, with any individual industry highly concentrated geographically, but with immobile factors of production. Economies of this kind are, in fact, a staple of theoretical models of international trade in the presence of external economies. The US economy, however, is characterized by high mobility of capital and labour as well as of goods and services. Economic and monetary union will ensure high mobility of capital within Europe; it remains to be seen whether the Single European Act will eventually result in mobile labour or whether language and cultural barriers will continue to make European labour relatively immobile.

What is the effect of increased factor mobility? I will argue first, that high mobility of capital in particular tends to magnify regional economic fluctuations; and second, that high mobility of both capital and labour tends to produce divergent economic growth over time.

The first point is fairly obvious. Consider a region that is highly specialized, relying on a few industrial clusters for its exports to other regions. A positive shock to the demand for the products of these clusters will ordinarily raise the expected return on investment in the region. If capital were immobile, this increase in investment demand would primarily be reflected in a rise in the regional cost of capital. With mobile capital, however, the result will be an inflow. (It is, in fact, more usual than not for export booms driven by external demand to produce current account deficits rather than surpluses; see the comparison of Puerto Rico and Portugal by Eichengreen (1990), which is discussed further in Section 3.) As long as some of the capital expenditure falls on non-traded goods, this will have an accelerator effect that increases the impact of export fluctuations on regional employment, both in booms and in slumps. 
The point about long run growth is a little more subtle, or at least unfamiliar. Again consider a situation in which industries are geographically concentrated but factors of production are immobile. Suppose that in such a situation a region received an adverse shock to the demand for its export industries. The effect would be to drive down the relative wages and other factor costs in the region; but this would attract additional employment, and perhaps allow the region to snatch some industrial clusters away from other, higher-cost regions. There would therefore be some mean reversion in terms of gross regional product: regions that have been unlucky in their heritage of industries from the past will have lower costs than lucky regions, and will therefore be more likely to break into industries in the future. We would expect this process to put limits on the extent of regional divergence in growth. ${ }^{3}$

Suppose, on the other hand, that factors of production are highly mobile. Then an unfortunate region will not have lower factor prices for very long: capital and labour will move to other regions until factor payments are equalized. This means, however, that there is no particular reason to expect a region whose traditional industries are faring badly to attract new industries. It can simply shed people instead. The implication is that relative output and employment of regions should look more like a random walk than like a process that returns to some norm.

Note that this argument is rather different from the standard idea of uneven development or core-periphery formation, in which divergent growth emerges as a deterministic process because initially successful regions enjoy a cumulative advantage over initially less successful regions. While many authors, myself included, have emphasized the possibility of such even development, the growth of the sunbelt in the USA and in the Iberian countries suggests that such systematic unequalizing forces are not strong in today's industrial world. The story is instead one in which the point is not the existence of a strong force for divergence but the absence of a force for convergence of output and employment (factor prices and per capita income do converge). As a result, random shocks just cumulate over time. This corresponds to Henry Ford's characterization of history as 'one damn thing after another'.

I have argued, then, that the combination of 1992 and EMU will produce a European economy that is (a) more subject to region-specific shocks, because in an integrated market regions will become more specialized and (b) likely to exhibit greater disparity in regional growth rates, because with increased factor mobility regions will tend to adjust to shocks by adding or shedding resources rather than by adding or shedding industries. 
So far, however, this is just a theoretical argument. Next I turn to a survey of some relevant evidence.

\section{Evidence on integrated markets and monetary unions}

Analysts of potential developments in Europe are fortunate in having a reasonably good model: the United States. The US shows how a continent-sized single market and currency union works in practice, and both examining that example and contrasting it with the EC offers considerable insight. Admittedly, there are some differences - the language and cultural uniformity of the US will not be matched by Europe in the forseeable future. Nonetheless, I will focus on the US-EC comparison to buttress my case on three issues. First is the proposition that an integatrated market leads to greater specialization at the regional level. Second is the proposition that this specialization leads to greater short-run regional instability, an instability reinforced by capital mobility. Finally, we need to document the proposition that long-run growth tends to be more divergent in an integrated market with high factor mobility.

\subsection{Regional specialization}

In some earlier work (Krugman 1991) I made a crude comparison of regional specialization in the US and in Europe. Regions were defined at a very aggregate level, exploiting the fact that the 'Great Regions' of the US - the North-east (New England plus Middle Atlantic), the Mid-west (East North Central and West North Central), the South, and the West - are comparable in population and economic size to the four major European countries. So if policy regimes had been comparable we might have expected a roughly similar degree of economic differentiation among major US regions and among major European countries. Indeed, we might have expected localization to have proceeded further in Europe, if only because the distances involved in the US are so much larger. The analysis above suggests, however, that because of the history of trade barriers we should find European nations less specialized than US regions.

The comparisons reported below use employment statistics for (more or less) two-digit industries for European countries, which can be compared with regional employment statistics for (more or less) the same industries for US regions.

Using this data, indices of regional/national divergence are constructed as follows. Let $s_{i}$ be the share of industry $i$ in total manufacturing employment in some region/country; and let an asterisk indicate that we 
Table 8.1. Indices of industrial specialization

\begin{tabular}{lccrc}
\hline \hline US regions, 1977 & North-east & Mid-west & South & West \\
\hline North-east & - & 0.224 & 0.247 & 0.242 \\
Mid-west & - & - & 0.336 & 0.182 \\
South & - & - & - & 0.271 \\
\hline
\end{tabular}

EC countries, 1985

\begin{tabular}{lllrl} 
& France & $\begin{array}{l}\text { Federal } \\
\text { Republic } \\
\text { of Germany }\end{array}$ & Italy & $\begin{array}{l}\text { United } \\
\text { Kingdom }\end{array}$ \\
\hline France & - & 0.200 & 0.197 & 0.083 \\
Federal Republic of Germany & - & - & 0.175 & 0.184 \\
Italy & - & - & - & 0.184 \\
\hline
\end{tabular}

Sources: US Census of Manufactures, 1977.

are referring to some other region/country. Then the index is

$$
\Sigma_{i}\left|s_{i}-s_{i}^{*}\right|
$$

Suppose that two regions had identical industrial structures, i.e., that shares of employment were the same for all $i$, then the index would be zero. A little less obviously, if two regions had completely non-overlapping industry structures, the index would be 2 (because each share in each region would be counted in full). So the index is a rough way of quantifying differences in structures, and hence regional specialization.

This index was calculated for twelve pairs of regions/countries: for US regions compared with one another, and for Europe's big four compared with one another. The results are shown in Table 8.1 .

In spite of greatly excessive aggregation both of industries and of geographical units, the basic result is clear: European nations are less specialized than US regions.

The result can be emphasized by focusing on two particularly revealing cases: the specializations of the Mid-west and the South, on the one hand, and of Germany and Italy, on the other. In both cases we are, in effect, comparing a traditional heavy industrial producer with a traditional light, labour-intensive producer. And as we see in Table 8.2, which compares employment shares in selected sectors, the patterns of revealed comparative advantage in key industries are similar. 
Table 8.2. Industrial specialization, 1985. (Percent share of manufacturing employment)

\begin{tabular}{|c|c|c|c|c|}
\hline & Germany & Italy & Mid-west & South \\
\hline Textiles & 3.7 & 9.1 & 0.3 & 11.7 \\
\hline Apparel & 2.6 & 5.6 & 2.4 & 10.6 \\
\hline Machinery & 15.8 & 12.9 & 15.0 & 7.1 \\
\hline Transport equipment & 13.2 & 10.4 & 12.8 & 5.9 \\
\hline $\begin{array}{l}\text { Sum of share differences } \\
\left(\sum_{i}\left|s_{i}-s_{i}^{*}\right|\right)\end{array}$ & \multicolumn{2}{|c|}{35.2} & \multicolumn{2}{|c|}{62.6} \\
\hline
\end{tabular}

But the degree of specialization in accord with this revealed comparative advantage is very different. At one extreme, the Mid-west has essentially no textile industry, compared with Germany's still substantial one. At the other, the South produces far less machinery than Italy.

A final illustrative comparison involves the automotive industry. Table 8.3 compares the regional distribution of the US auto industry with the national distribution of the European industry. What it shows is that the US industry is far more localized. (In essence, the US industry is a Mid-western phenomenon, with only a scattering of assembly plants in other parts of the country.)

These are at best illustrative comparisons. Other work on US data, and recent US experience, shows that such aggregative numbers fail to do justice to the subtleties and yet crucial significance of regional specialization. To take the most obvious example, aggregate industry statistics lump together a variety of electronics-related sectors in such a way that tests for geographic concentration fail to reveal the existence of either Silicon Valley or Route 128. Yet not only are these agglomerations very

Table 8.3. Distribution of automobile production, 1985. (Percent share of total production)

\begin{tabular}{lrlr}
\hline \hline United States of America & & European Community \\
\hline Mid-west & 66.3 & Germany & 38.5 \\
South & 25.4 & France & 31.1 \\
West & 5.1 & Italy & 17.6 \\
North-east & 3.2 & United Kingdom & 12.9 \\
\hline \hline
\end{tabular}

Source: Motor Vehicle Facts and Figures, Detroit: Motor Vehicle Manufacturers' Association, 1988. 


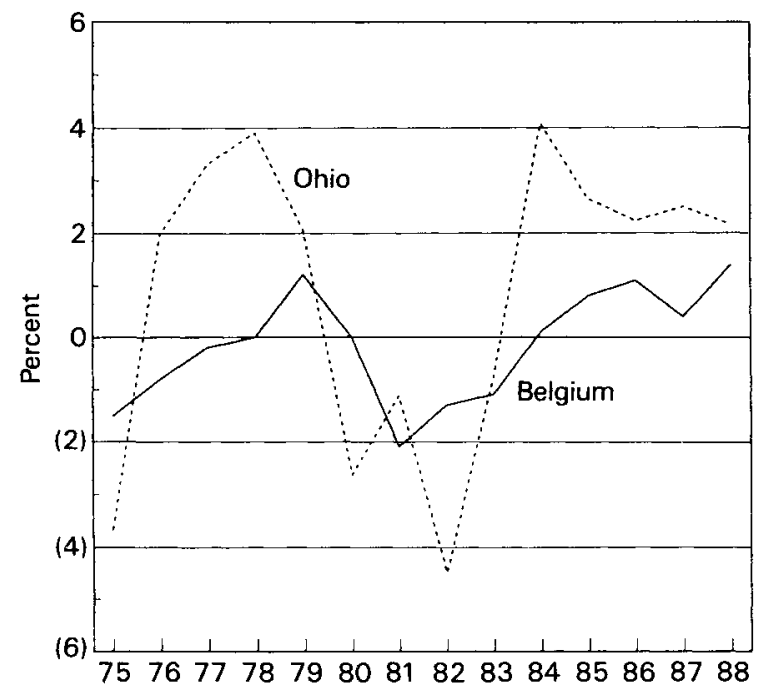

Figure 8.2 Annual rates of employment growth, Ohio and Belgium

Sources: US Department of Labor, Handbook of Labor Statistics, 1989; OECD, Main Economic Indicators, Historical Statistics, 1990

real, they are sharply distinct, to such an extent that the severe slump that hit the Massachusetts industry was hardly felt in the West. While I cannot document this, it is hard to escape the impression that regional specialization at a very fine-grained level has gone considerably further in the US than in Europe. ${ }^{4}$

\subsection{Short-run growth}

A full analysis of the prevalence of short-term region-specific shocks would require a fairly elaborate analysis. In particular, I would like to see a study along the lines of the recent paper by Blanchard and Katz (1992) carried out in tandem for comparably-sized geographical units in the US and in Europe. In this chapter I will restrict myself to an illustrative comparison, in order to provide some suggestive support for the proposition that regional shocks are larger in the highly specialized regions of the US, than they are in Europe.

The comparison is between the state of Ohio and the nation of Belgium. Both are old industrial areas, located in their continent's 'rust belt'; both are essentially manufacturing areas. (Illinois would have been in some ways a more obvious candidate, but the presence of the large service- 


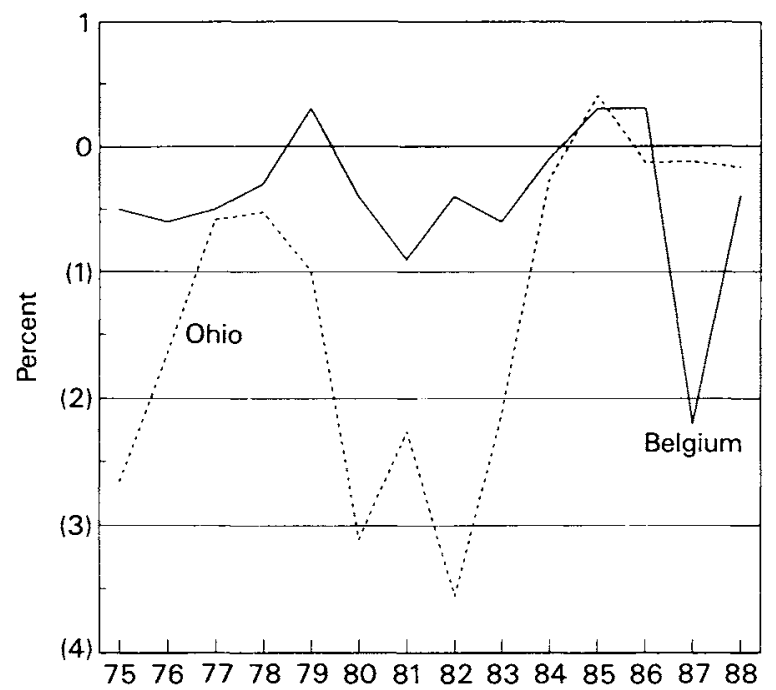

Figure 8.3 Adjusted rates of employment growth, Ohio and Belgium

exporting metropolis of Chicago makes it less than comparable with any small European nation.)

It is immediately apparent that employment growth is much more unstable in Ohio than in Belgium. Figure 8.2 compares annual rates of growth of employment in the two areas from 1975-88; evidently Ohio has experienced much more variation. The standard deviation of the Ohio growth rate is 2.75 compared with 1.05 for Belgium.

To some extent the greater instability in Ohio can be attributed to the instability of the US economy as a whole: over the period, the standard deviation of employment growth in the US was 1.69 compared with 1.02 for the European Community. To correct for this, Figure 8.3 compares two differences: the difference between the growth in Ohio employment and US employment on the one hand, and the difference between Belgian and EC employment growth, on the other. Although the contrast between the two is now somewhat less, this normalized Ohio employment growth is still substantially more variable, with a standard deviation of 1.23 compared with 0.61 for Belgium.

This is hardly a conclusive demonstration. We need to do a global comparison rather than focus on a single pair of regions, and we need to do a more elaborate time series analysis rather than assume that first differences are a sufficient statistic. Nonetheless, Figures 8.2 and 8.3 help confirm the point that the specialization of US regions leads to greater instability in regional economies. 


\subsection{Long run growth}

In their illuminating recent paper, Blanchard and Katz (1992) have produced a striking set of stylized facts about growth at the state level within the United States. The picture that emerges is one of large differences in growth rates that are, however, almost entirely due to differences in the rate of employment growth rather than to changes in relative income per worker or per capita. We may, for example, compare the two largest states: from 1960-88 employment in California rose $86 \%$ relative to employment in New York, but the relative per capita income of the two states was unchanged. As Blanchard and Katz point out, this is consistent with the view that US states are subject to large, persistent shocks, to which they adjust through migration rather than changes in wage rates.

The Blanchard-Katz time series analysis suggests, in fact, that the conventional international adjustment mechanism, in which countries that suffer adverse shocks restore full employment through real depreciation, is virtually absent within the United States. While wages do decline somewhat in states that suffer adverse shocks, there is no discernible tendency for states to recover lost jobs. Instead, workers simply move out until the unemployment rate falls to its normal level.

The historical European adjustment process has been completely different. Table 8.4 makes the point, comparing the rates of employment growth in major US states and in the major EC countries. In spite of images of 'Bread and Chocolate' and political tensions over immigrants, migration has played very little role in European countries. Instead, real wages have adjusted so as to allow employment in each country to grow at roughly the rate of natural increase of the employable population. The slowest-growing major EC country, the UK, has maintained almost exactly the same rate of employment growth as the EC average.

The result has been that even though rates of growth in per capita income and productivity are more nearly equal among US states than among European countries, the spread of overall growth rates is much larger: over the 1960-88 period real gross domestic product (GDP) in the slowest-growing major EC country, the UK, grew at $2.5 \%$ compared with $4 \%$ for Italy, a difference of $1.5 \%$. Over the same period, US sunbelt states on average grew more than $3 \%$ faster than old industrial states in the North-east.

The obvious implication, then, is that if Europe moves toward US levels of regional specialization and factor mobility, disparities in economic growth rates among countries and regions can be expected to increase substantially. 
Table 8.4. Annual rates of employment growth, EC and USA, 1960-88

\begin{tabular}{lc}
\hline \hline European Community & 0.3 \\
France & 0.5 \\
Italy & 0.1 \\
United Kingdom & 0.3 \\
United States of America & 2.2 \\
California & 3.2 \\
New York & 1.0 \\
\hline
\end{tabular}

The next question is how likely the increases in regional instability and in growth disparities will affect the need for policy intervention.

\section{Integration, monetary union and stabilization policy}

If regional shocks are likely to be larger in a more integrated and unified Europe, we might be tempted to look to the possibilities of regional stabilization policies. There are then three points that need to be made. First, within a monetary union stabilization policy must take the form of fiscal intervention. Both logic and US experience suggest, however, that regional governments in an integrated market with high factor mobility will be unable to pursue counter-cyclical fiscal policies, and will indeed tend to act pro-cyclically. This then puts the weight of stabilization at the regional level on fiscal actions, both automatic and deliberate, at a higher level; essentially fiscal federalism is the major regional stabilizer within the US, and the minor size of the EC budget poses questions about how an integrated $\mathrm{EC}$ economy will actually function.

\subsection{The primacy of fiscal policy}

It is a familiar point, but one perhaps worth re-emphasizing, that in a monetary union old-fashioned Keynesianism with its emphasis on fiscal policy comes back into its own. Aggregate monetary policy can stabilize aggregate demand shocks, but region-specific demand shocks resulting from changes in tastes and technology cannot be smoothed out in this way. By definition, countries and regions have no monetary policy. At the same time, with the high capital mobility that goes with EMU there should be little crowding out from fiscal expansion because the regional money supply will automatically accommodate the expansion.

The only reason to suspect that regional fiscal policy might be ineffective would be the argument that in highly integrated markets any increase in 
regional spending would fall primarily on goods produced elsewhere - in effect, that the multiplier would be very small. At first sight, such figures as are available would seem to confirm this; for example, Eichengreen (1990) found that the ratio of imports (goods and services) to GDP in Puerto Rico was more than 0.6. In a way, however, this high ratio is misleading, because it consists to a large extent of imports of intermediate goods. A more relevant number is the share of value-added or employment generated by sectors that are essentially oriented to the local market rather than national or international markets. While it is difficult to make such estimates rigorously, most studies have found that even within the US more than half of a state's output and work force is oriented toward the internal market. (As a recent example, see Porter's (1991) study of Massachusetts.)

So the natural tool of regional stabilization is fiscal policy. Unfortunately, in an integrated market this tool tends to become largely unavailable.

\subsection{The immobility of local fiscal policy}

It is an initially surprising fact that state governments in the US make no effort to use their budgets as a stabilization tool. In fact, almost without exception they disconnect even the automatic stabilizers: every state but Vermont has the requirement that the budget should be balanced. ${ }^{5}$ Thus state level fiscal policy moves in a strongly pro-cyclical direction, magnifying regional booms and slumps.

It could be the case that the insistence on budget balance at the state and local level is the result of conservative prejudice, and that within an EMU the more sophisticated European governments would follow more stabilizing policies. We may, however, offer another hypothesis: that the insistence on budget balance reflects a more or less appropriate response at the state level to the realities of the regional business cycle.

Why should state governments follow a policy of continuous budget balance? We may note, first, that to the extent that state business cycles are associated with national fluctuations in employment, states can rely on national monetary policy to do the stabilizing role. This job will not be done perfectly, but state governments are unlikely to be able to secondguess the Federal Reserve productively.

When we turn to state-specific shocks, we can argue that it would be appropriate for a state to use borrowing to offset any decline in revenue that results from a temporary downturn in the state economy. But as noted above, it appears that at the state or regional level there is essentially no such thing as a temporary downturn! That is, the Blanchard and 
Katz evidence (1992) suggests that states work their way out of high relative unemployment not by increasing employment but by reducing their labour force. If a state does badly relative to the national average in one period, there is no reason to expect it to compensate with an exceptionally good performance later.

Putting these arguments together, we see that there may be little case for attempting to make a stabilizing state or regional fiscal policy possible. Responding to aggregate shocks is not part of the state's appropriate role; responding to state-specific shocks could easily become fiscally irresponsible, since such shocks tend to be permanent. Thus the costs of pro-cyclical fiscal policy that result from a constitutional prohibition on deficits may be outweighed by the advantages of enforced responsibility.

The problem with all of this is that while factor mobility is high, it is not instantaneous. If workers could instantly move from distressed regions to successful ones, then there would be no case for regional stabilization policy. Given the transition periods - Eichengreen (1990) estimated that only $40 \%$ of a region-specific unemployment shock is eliminated each year; Blanchard and Katz found that after a state-specific shock, unemployment actually grew for a time and then took six years to fade away - there is still a case for some counter-cyclical policy at the regional level.

In the US, this role is largely played by automatic stabilizers resulting from the importance of the Federal budget.

\subsection{Federalism as an automatic stabilizer}

It is straightforward to see how the role of a large Federal budget acts as a stabilizer of regional economies. Consider a regional economy that may be described in the short run by an old-fashioned multiplier model:

$$
\begin{aligned}
Y & =C+I+G+X-M \\
C & =(1-s)(1-t) Y \\
M & =m Y
\end{aligned}
$$

But suppose that taxation and government spending may be split into two parts. Some taxes are Federal, others state:

$$
t=t_{F}+t_{s}
$$

And while Federal spending in the region can be taken as given, state spending must be adjusted to equal state tax revenue: ${ }^{6}$

$$
G=G_{F}+t_{s} Y
$$


It then follows that the multiplier on changes in regional exports is

$$
\frac{d Y}{d X}=\frac{1}{1-t_{s}-(1-s)(1-t)}
$$

It is immediately apparent that for any given overall level of taxation, the multiplier is larger the greater the share of taxes that is collected at the state or regional (or, in the European context, national) level. That is, a system with little fiscal federalism will have a harder time coping with the instability of exports from highly specialized regions than a system like that of the US, with its largely Federal systems of social insurance, defence, and so on.

We have argued, then, that greater integration of markets and greater factor mobility, together with the loss of national monetary policy, will create new problems of stabilization at the European regional level. The United States has long had these problems. While the US does not cope with the problems perfectly (as the current travails not only of New England but of the North-east, in general, and increasingly also of California, demonstrate) a highly federalized fiscal system helps a good deal. The lack of such a system in Europe therefore is a real problem.

This may seem to be an unusual focus for a discussion of regional issues. Most regional analysis focuses not on problems of stabilization but on longer run issues of development, and on equalizing versus unequalizing forces. While I have not made these issues central, I conclude the chapter with a brief discussion of these more traditional concerns.

\section{Development and regional inequality}

This chapter has followed Blanchard and Katz (1992) in supposing that large differences in growth rates among US regions are generated by a largely random process. Integrated markets lead to regional specialization along essentially arbitrary lines, but with the pattern of specialization then locked in by external economies. When random shocks to demand or technology benefit some regions at the expense of others, factors of production migrate to the successful regions, short-circuiting the mechanisms that might otherwise have led these regions to acquire new specialties.

This mechanism is somewhat in contrast to models of uneven development in which a systematic process leads to growth differences. In the familiar view, which can be formalized in terms of both endogenous growth models like those of Grossman and Helpman (1991) and in terms of models of economic geography, success and failure are self-reinforcing through external economies that apply at a level that extends beyond that of individual industries. For example, successful regions will generate 
backward linkages, not simply within industries for their specific intermediate products, but across all industries because of the geographic concentration of population and purchasing power. Similarly, they may generate forward linkages through the availability of general purpose inputs such as power and transportation. I have argued (Krugman 1991) that such large-scale linkages explain the nineteenth century emergence of a concentration of US manufacturing in a narrow stretch of the Northeast and inner Mid-west.

Why, then, does the argument in this chapter focus on the milder random mechanism? The basic answer is that at least since World War II the experience of regional growth, both in the US and in Europe, has suggested that the forces tending to generate a core-periphery pattern have reached their limit or may even be weakening. In the US the traditional manufacturing belt is both spreading to the south and facing growing competition from other areas; in Europe there has been a process of convergence between north and south.

Why this should be the case is less clear. It may be that new technologies of transportation and communication make it easier for industries to flee high land costs and take advantage of immobile labour in peripheral regions that prefers to receive low wages at home rather than migrate to take advantage of high wages at the centre. This is, however, speculative at this point. What is clear is that in the US the employment shares of the traditional manufacturing states have been steadily declining since World War II. Thus we need to postulate a mechanism for uneven growth that does not predict that past success is always self-reinforcing.

This does not mean that all of the issues associated with core-periphery stories become irrelevant. The main policy concern in regional economics is with the fate of those workers who, for whatever reason, are immobile, and who can end up stranded in a declining region - the Mezzogiorno problem. Essentially the same social and distributional problems arise, however, when the decline of a region simply reflects specialization in what turns out to be the wrong product - Detroit does not present any prettier a picture than Appalachia.

In this chapter, however, I will simply avoid the question of what the policy response to this kind of regional issue should be, for three reasons. First, it is much less related to the EMU than the stabilization problem. Second, it would need an entirely separate paper. Finally, I do not at present have any useful ideas to offer!

\section{Summary and conclusions}

Since official documents on EMU tend to focus only on the potential benefits, academics have an obligation to point out various clouds that 
may go with the silver lining. This chapter falls in that category. It does not argue that EMU will be a bad thing, but it points out that the combination of 1992 and EMU will tend to produce some new stabilization problems at the regional level.

Theory and the experience of the US suggest that EC regions will become increasingly specialized, and that as they become more specialized they will become more vulnerable to region-specific shocks. Regions will, of course, be unable to respond with counter-cyclical monetary or exchange rate policy. Furthermore, in an environment of high factor mobility such shocks will tend to have permanent effects on output, which will tend to immobilize fiscal policy as well.

In the US the heavily federalized fiscal system offers a partial solution to the problem of regional stabilization. Unless there is a massive change in European institutions, this automatic cushion will be absent.

None of this is an argument against EMU. Some advocates of EMU seem to suggest, however, that every aspect of policy management will become easier. But as virtually any US state governor can attest, an integrated continental market does not solve all local problems, and can even make some of them worse.

\section{NOTES}

1 The recent EC document 'One Market, One Money' (European Commission, 1990) addresses this issue, but in a one-sided way. Section 6.2 is entitled 'Will asymmetric shocks diminish in EMU?'; the possibility, and indeed the likelihood, that such asymmetric shocks will actually increase is not even contemplated.

2 This can be justified by a limit-pricing argument in the face of an alternative source of supply. It has the unfortunate effect of eliminating any possibility of forward linkages via supply of intermediates, which can only be brought back in a model with a more elaborate market structure (see Krugman 1991).

3 A highly stylized formulation of international competition with external economies but immobile factors is given in Krugman (1987). In that formulation, historical accident can have persistent effects on the relative income of two countries/regions, but only over a limited range. The reason for the limit is that with sufficiently low relative wages a region can, as suggested in the text, start to snatch other regions' industrial clusters.

4 One problem with asserting that an integrated Europe will become more specialized, however, is that US statistics show that regional specialization has been declining since World War II (see Krugman 1991, ch. 3). I suspect, however, that this is largely statistical illusion; specialization may have become more difficult to measure, but not necessarily less in fact.

5 Actually, matters are a bit more complicated. What is required is usually not a balanced budget, but the maintenance of a state balance. That is, states maintain what amounts to a bank account; they can use surpluses to increase this account, and draw it down in times of need, but are forbidden to go into 
debt. In principle, they could practice counter-cyclical policies by building up the accounts in good years, then drawing them down in bad; but few do this. Adding to the confusion is the proliferation of quasi-autonomous agencies, which are allowed to borrow and which in effect allow states to go into debt after all. For example, toll highways are typically financed by bond issues; other capital spending may be financed by borrowing backed by a special allocation of revenue. Last year the government of New York offered a classic example of how to evade its budget restrictions by creating a dummy agency which borrowed money to buy Attica prison from the state, which then leased the facility back for a fee sufficient to cover the debt service. In spite of abuses, however, it is not too misleading to think of states as running balanced budgets.

6 State budgets could be balanced either by adjusting spending or by raising taxes. I choose the 'read my lips' assumption for convenience.

\section{REFERENCES}

Blanchard, O. and L. Katz (1992) 'Regional Evolutions', in Brookings Papers in Economic Activity, 1.

Eichengreen, B. (1990) 'One Money for Europe? Lessons from the US Currency and Customs Union', Economic Policy, 10, pp. 118-87.

Commission of the European Communities (1990) One Market, One Money: an Evaluation of the Potential Benefits and Costs of Forming an Economic and Monetary Union, European Economy, 44 (October).

Grossman, G. and E. Helpman (1991) Innovation and Growth in the Global Economy, Cambridge, Mass.: MIT Press.

Krugman, P. (1987) 'The narrow moving band, the Dutch disease, and the competitive consequences of Mrs. Thatcher', Journal of Development Economics, 27: 41-55.

Krugman, P. (1991) Geography and Trade, Cambridge, Mass.: MIT Press.

Porter, M. (1991) A competitive strategy for Massachusetts, mimeo, Harvard Business School. 